\title{
O CONCEITO DE CÍRCULO CRIATIVO: PORQUE A VIRAGEM LINGUÍSTICA INTERESSA FILOSOFICAMENTE AO DIREITO DE AUTOR
}

\section{THE CONCEPT OF CREATIVE CIRCLE: WHY THE LINGUISTIC TURN IS PHILOSOPHICALLY INTERESTING TO COPYRIGHT}

\author{
VICTOR GAMEIRO DRUMMOND \\ Pós-doutor em Direito pela FDUL. Doutor em Direito pela UNESA. Mestre em Direito pela FDUL. \\ Professor do Programa de Mestrado em Direito da Faculdade Guanambi. \\ Guanambi / Bahia \\ victor@victordrummond.com
}

\begin{abstract}
RESUMO
Um dos elementos mais significativos e discutidos nas análises doutrinárias referentes à proteção das criações humanas pelo direito de autor é a justificativa para tal proteção, em especial sob a forma de exclusividade. Os elementos trazidos à discussão pela doutrina inserem-se em valores econômicos e não exploram as condições filosóficas. Trata-se muito de discutir o equilíbrio na proteção e o uso das obras por razões econômicas. Considerando-se que a hermenêutica é o mais justo e efetivo meio para alcançar a verdade filosófica, seria mais apropriado incorporar a hermenêutica contemporânea ao direito de autor para se decidir sobre a aplicabilidade dos direitos exclusivos.
\end{abstract}

Palavras-chave: Crítica Hermenêutica; Círculo Hermenêutico; Direito de autor

\begin{abstract}
One of the most significant and most widely discussed elements of the doctrine stipulating the protection of human creations by copyright law is the justification for such protection, particularly when it allocates exclusive rights to the creator. The doctrine is principally based on economic values and does not take into account a philosophical perspective; instead, it considers the equilibrium between protection and the use of people's work for economic purposes. Given that hermeneutics is the fairest and most effective way to search for philosophical truth, it would be more appropriate to incorporate contemporary hermeneutics into copyright law when deciding on the allocation of exclusive rights.
\end{abstract}

Keywords: hermeneutics; copyright; creation; exclusive rights.

\section{SUMÁRIO}




\section{INTRODUÇÃO}

Um problema de grande monta no campo do direito de autor é a análise das justificativas filosóficas para que um sujeito que atue por meio do processo criativo possa ser protegido, com exclusividade, por meio de atribuições de direito por fazer surgir uma criação do domínio das artes, da cultura e/ou das ciências.

Este aspecto elementar do direito de autor é, em verdade, o próprio fundamento de sua existência, uma vez que se alguém deve ser remunerado, compensado ou premiado por algo que criou, deve ser justificada esta circunstância do ponto de vista filosófico.

As justificativas porém, tem se baseado no equilíbrio da equação entre o que é "dado" ao criador pela sociedade (considerando que o mundo está posto antes de sua chegada) e o que o criador consegue criar por sua capacidade subjetiva de criação (portanto, considerando sua condição de ser-no-mundo como um criador).

Ou seja, se o criador não cria “absolutamente sozinho" (pois há algo que já está posto antes de sua "chegada" ao mundo) ao mesmo tempo as obras não estão simplesmente prontas e à disposição de todos (já que há necessidade de tradução do meio sensível ao inteligível) e, portanto, deve haver uma participação subjetiva, mas também uma valoração da ordem do ambiente que o sujeito ocupa.

A tendência doutrinária praticada pelo senso comum autoralista é de atuar buscando uma justificativa em filósofos que, tenham ou não tratado de discutir o direito de autor, trazem contributos ao direito de autor somente uma vez que tal categoria esteja posta. A análise pois, se dá numa análise a posteriori ou ex post facto, para usar duas expressões difundidas por Drummond $^{1}$ e Suthersanem ${ }^{2}$, respectivamente. No fundo, portanto, busca-se justificativas para

\footnotetext{
${ }^{1}$ DRUMMOND, Victor Gameiro. Os privilégios monopolistas como elementos comuns para os sistemas de Copyright e de Droit D'auteur e o déficit filosófico do direito de autor. In: VICENTE, Dário de Moura (coord.). Estudos de Direito Intelectual em Homenagem ao Professor Doutor José de Oliveira Ascensão: 50 anos de vida universitária, Coimbra: Almedina, 2015. p. 601-625.
} 
VICTOR GAMEIRO DRUMMOND

explicar o comportamento mercadológico do direito de autor ou simplesmente para indicar porque um ou outra atividade do setor criativo é justa ou adequada.

O objetivo deste texto é apresentar uma nova justificativa filosófica amparada na hermenêutica contemporânea e que atende aos fundamentos do direito de autor, sem propor a discussão de razões de ordem econômica e desviantes da pura justificativa filosófica. Para tal, a metodologia utilizada foi a revisão bibliográfica de autores e outros textos jurídicos concernentes a temática.

\section{ESTADO DA ARTE DAS JUSTIFICATIVAS FILOSÓFICAS PARA O DIREITO DE AUTOR}

Os autores que pretendem analisar, filosoficamente, o porquê da aplicação do direito de autor dividem e classificam as hipóteses de justificativa em padrões mais ou menos repetidos.

O senso comum autoralistas, pois, viu por bem indicar as justificativas filosóficas (mas que, muitas vezes, possuem condão histórico) seguindo uma classificação ou potencialidade de atribuição de escolas desenvolvidas por determinados filósofos, em adaptações que, em maior ou menor medida, vão se repetindo. Estão quase sempre presentes Locke e Kant, além dos utilitaristas Bentham e J. S. Mill, bem como algumas vezes Marx, Fichte, Hegel e Rawls.

As escolas ou teses aplicadas são pouco variadas e têm como objetivo indicar os diferentes movimentos de adaptação das escolas/matrizes filosóficas apontadas ou, ainda, justificar a apreciação de teses mais contemporâneas.

Entre as mais tradicionais, encontram-se a tese utilitarista (baseada nas concepções de Bentham e J. S. Mill), a tese proprietarista, fundada no direito natural/laboral (teoria do trabalho-propriedade de matriz lockeana), e a tese personalista/moralista de matriz kantiana (e, também, com alguma incidência e influência de Fichte e Hegel).

Estas três vertentes servem como objeto de crítica e justificam a escolha de uma nova via pela hermenêutica contemporânea, que é a pretensão deste estudo.

No tocante a cada um delas, suas ideias primordiais devem ser indicadas.

Quanto ao utilitarismo de Mill e Bentham, o senso comum autoralista que trata de utilizar tais pensadores como base ideológica para a justificativa filosófica para o direito de autor busca

2 SHUTERSANEN, Uma, A Stakeholder's Palimpsest. In F. Macmillan (coord.), Copyright Law: New Directions in Copyright Law. London: Edward Elgar, 2007. P. 119-135. 
O CONCEITO DE CÍRCULO CRIATIVO: PORQUE A VIRAGEM LINGUÍSTICA INTERESSA FILOSOFICAMENTE AO DIREITO DE AUTOR

VICTOR GAMEIRO DRUMMOND

adaptar a ideia de que o principio da maior felicidade seria plenamente aplicável ao direito de autor. Desta forma, o autor poderia e deveria ser remunerado pelo fato de que a sua remuneração seria um estímulo para que o mesmo continuasse a criar. 0 principio da maior felicidade teria também a função de estimular a circulação das obras. Em uma ou outra medida, o preâmbulo do Estatuto da Rainha Ana de 1710 é citado como uma comprovação do viés utilitarista do direito de autor positivo, ao dispor esta ideia com vias a incentivar e estimular o processo criativo "[...] para o incentivo dos homens aprenderem a compor e escrever livros úteis $[\ldots]^{33}$.

Dentre os autores que indicam o utilitarismo como uma justificativa positiva para o direito de autor está Barboza ${ }^{4}$. 0 autor mexicano afirma que a tese para a justificativa utilitarista (ou de interesse público) decorre do entendimento presente na common law de que "os direitos de autor não se derivam do direito natural, mas sim de um ato de legislatura". ${ }^{5} \mathrm{~A}$ felicidade, ao fim e ao cabo, é a busca de todo o processo legislativo e, por outro lado, haveria um utilitarismo decorrente da própria constituição norte-americana que pretende ver na proteção do direito de autor um estímulo ao desenvolvimento da cultura e do ser humano. Também entende como razoável a tese utilitarista o autor norte americano William Fisher. ${ }^{6}$

No que se refere às teses lockeanas, estas vem sendo utilizadas como fundamento filosófico não somente para o direito de autor, mas para todo o gênero denominado propriedade intelectual. 0 principal argumento dos autoralistas defensores das ideias lockeanas (principalmente derivadas do capítulo 5 do Segundo Tratado do Governo Civil de Locke) é a tese de que a transferência de algo que possa ser considerado um bem comum deveria ser objeto de uma nova condição jurídica que, neste caso, é exatamente a exclusividade decorrente do direito de autor. Ou seja, uma vez que algo esteja presente no mundo perceptível dos sentidos e seja apropriado por alguém, este possui o direito exclusivo de fazer uso de sua criação, pelo fato de que, com o seu trabalho, transformou algo que seria considerado um bem comum em uma criação. No caso de Locke, os exemplos se referem às terras e produtos da mesma, como frutas.

3 Disponível em: <http://www.copyrighthistory.org/cam/tools/request/showRecord.php? id=record_uk_1710 $\geq$, Acesso em 03. out. 2016.

${ }^{4}$ BARBOSA, Roberto Garza. Derechos de autor y derechos conexos: marco jurídico internacional, aspectos filosóficos, sustantivos y de litigio internacional. Ciudad de México: Porrúa, 2009. p. 11.

${ }^{5}$ BARBOSA, Roberto Garza. Derechos de autor y derechos conexos: marco jurídico internacional, aspectos filosóficos, sustantivos y de litigio internacional. Ciudad de México: Porrúa, 2009. p. 13.

${ }^{6} \mathrm{FISHER}$ William, Theories of intellectual property. Disponível em: <http://cyber.law.harvard.edu/people/tfisher/iptheory.pdf>. Acesso: 20. set. 2016. 
O CONCEITO DE CÍRCULO CRIATIVO: PORQUE A VIRAGEM LINGUÍSTICA INTERESSA FILOSOFICAMENTE AO DIREITO DE AUTOR

VICTOR GAMEIRO DRUMMOND

O exemplo da maçã retirada da árvore e que passa a ser propriedade do seu coletor pelo simples fato do trabalho é o mais utilizado pelo senso comum autoralista. Entre os autores que incluem Locke como uma fonte fidedigna filosófica para justificar o direito de autor encontram-se, entre outros: Merges ${ }^{7}$ e Drahos ${ }^{8}$. Merges entende que Locke apresenta uma simples, porém convincente, história original sobre a apropriação ${ }^{10}$ enquanto Drahos, por sua vez, não propõe uma teoria de compreensão da propriedade intelectual ${ }^{11}$. Drahos irá afirmar que "um instrumentalismo da propriedade não aspira a rever as estruturas profundas da propriedade ou de sua essência natural". ${ }^{12} \mathrm{E}$ vai além: "a propriedade, diz a atitude instrumentalista, serve a valores morais, mas não é a base de um valor moral". ${ }^{13}$ Ou seja, por mais que defenda as teses lockeanas, Drahos vai um pouco além e observa alguns exageros na adaptação de tais teses.

A terceira tendência filosófica que merece atenção é aquela decorrente do entendimento de Kant sobre o direito de autor. Ainda que não seja um texto fundamental em sua filosofia, o filósofo de Königsberg publicou o texto denominado "Da ilegalidade na reimpressão de livros" ${ }^{14}$ no ano de 1785 , e este texto iria de apresentar como um dos mais clássicos e relevantes estudos históricos sobre o direito de autor. No referido texto, Kant elaborou importantes questionamentos sobre a condição do autor e do editor, defendendo, em linhas gerais, que o editor possui direitos em detrimento de terceiros que não sejam autorizados a promover a

\footnotetext{
${ }^{7}$ MERGES, Robert P. Justifying intellectual property. Cambridge/London: Harvard University Press, 2011.

${ }^{8}$ DRAHOS, Peter. A philosophy of intellectual property. London: Ashgate Publishing Limited, 1996.

9 MERGES, Robert P. Justifying intellectual property. Cambridge/London: Harvard University Press, 2011.p. 305.

${ }^{10}$ No que lhe assiste razão decorrente da compreensão de que o bem retirado da natureza deixa de ser comum e passa a ser privado, mas amparado por determinadas condições de possibilidade, como, por exemplo, a proibição do desperdício.

${ }^{11}$ No comprehensive theory of intellectual property is proposed here. DRAHOS, Peter. A philosophy of intellectual property. London: Ashgate Publishing Limited, 1996. p. 1.

${ }^{12}$ An instrumentalism of property does not aspire to reveal the deep structures of property or its essential nature. DRAHOS, Peter. A philosophy of intellectual property. London: Ashgate Publishing Limited, 1996.p. 214.

13 Property, the instrumentalist attitude says, serves moral values, but is not the basis of moral value. DRAHOS, Peter. A philosophy of intellectual property. London: Ashgate Publishing Limited, 1996. p. 214.

${ }^{14}$ KANT, Imanuel. On the Injustice of Reprinting Books (original em alemão: Von der Unrechtmäßigkeit des Büchernachdrucks, publicado em 1785, disponíveis, tanto o texto original quanto a tradução em inglês, no endereço: <http://copy.law.cam.ac.uk/cam/tools/request/showRepresentation? id=representation_d_1785>. Verificar, também, a tradução e breves comentários ao texto na Revista do IBPI, $4^{\text {a }}$ edição, por Karin Grau Kuntz - Sobre a ilegalidade da reimpressão de livros. Disponível em: <http://www.wogf4yv1u.homepage.t-online.de/media/c1cd349287c9c15affff802bffffffef.pdf>. Acesso em: 03. out. 2016. Rio de Janeiro. Deve ser indicado também, que o termo alemão Unrechtmäßigkeit pode ser traduzido como ilegalidade, irregularidade, ilegitimidade ou injustiça. A edição em inglês está no mesmo sítio eletrônico do texto original digitalizado. Disponível em: <http://copy.law.cam.ac.uk>, como está acima especificado) e menciona a utilização da expressão injustice, mas também se pode encontrar a tradução unlawfulness.
} 
VICTOR GAMEIRO DRUMMOND

produção e distribuição de copias de obras. A proteção, portanto, não versava sobre o direito do criador, mas sobre o direito do editor que investia em material para promover a circulação das obras. O texto de Kant é altamente defensivo da condição do editor e pouco defensor, efetivamente, da condição do autor. Não obstante tal fato, Kant vem sendo apontado como o criador dos direitos morais do autor, pelo simples fato de indicar o autor como partícipe do processo criativo da obra.

Dentre os que entendem que Kant apresenta teses que justificam ao menos de modo razoável a aplicabilidade do direito de autor, estão Barbosa, Fisher e Merges.

Em síntese bem apertada, ainda assim pode-se afirmar que tanto as teses utilitaristas quanto as ideias lockeanas não foram originalmente criadas levando em conta fundamentos de direito de autor, mas sim, por outro lado, ideias genéricas e da ordem da filosofia que são forçosamente adaptadas para que possam parecer justificativas filosóficas efetivas para a aplicabilidade do direito de autor.

Já o texto de Kant, por sua vez, de fato tratava de elementos inerentes ao direito de autor.

Ainda assim, nenhuma destas teses é suficientemente densa no âmbito do direito de autor para justifica-lo como categoria jurídica e para responder à pergunta básica que é: por que se atribuir direito ao processo de criação?

Neste sentido, há de se observar que cada instituto jurídico - inclusive, no caso do direito de autor - possui (ou deveria possuir) um fundamento filosófico que o justifica, mas isso não quer dizer que tenha que ser construído uma espécie de leito de procusto por meio de adaptações de teorias filosóficas, seja para atribuir uma falsa e/ou artificial erudição ou para se alcançar o argumento da autoridade. É, porém, o que ocorre com cada uma das três principais justificativas filosóficas apresentadas pelo senso comum autoralista e citadas neste estudo que, como se observará, não são suficientes para justificar filosoficamente o direito de autor como categoria jurídica.

Nesse sentido, é evidente que, mesmo que se tome por exemplo que as questões referentes ao comportamento ético propostas por Kant possuem relevo no direito de autor (no mínimo, pela complexidade e difusão de seu conteúdo), como também a qualquer outra temática externa ao direito de autor, isso não significa o mesmo que dizer que suas ideias correspondam às mais adaptáveis e cabíveis ilações sobre a matéria e, ainda mais relevante, não significa que sejam a melhor resposta (ou a mais adequada) à categoria jurídica em análise. No mesmo sentido de insuficiência estão as teses decorrentes do utilitarismo (com a aplicação, por 
O CONCEITO DE CÍRCULO CRIATIVO: PORQUE A VIRAGEM LINGUÍSTICA INTERESSA FILOSOFICAMENTE AO DIREITO DE AUTOR

VICTOR GAMEIRO DRUMMOND

exemplo, do princípio da maior felicidade) de Bentham, e Mill ou mesmo, as teses proprietaristas de Locke. $^{15}$

Há, portanto, que se considerar não ser possível, para qualquer desses nomes apontados, atribuir-se uma teoria filosófica plena do/ao direito de autor. ${ }^{16}$ Por outro lado, não há que se reputar uma possibilidade, muitas vezes forçosa, para que sejam atribuídos elementos (ainda que significativos) de uma escola filosófica à filosofia do direito de autor.

Cabe o alerta de que nem toda tese filosófica é aplicável ou atribuível a outras categorias do conhecimento e, neste caso, ao Direito de um modo mais específico. Deve-se buscar a compreensão rigorosa das teses para que elas possam ser aplicadas, quando for o caso.

Neste aspecto, é importante salientar o fato de que o direito de autor assume inesperada complexidade no século XXI, em decorrência do advento das novas tecnologias e de suas consequências, como as complexas e facilitadas transferência e circulação de obras. 0 desenho social e das atividades humanas foi profundamente modificado com a chegada dessas novas tecnologias e, em especial, com a Internet, sendo evidente que esse (re)posicionamento social é suscetível de vários aportes filosóficos.

Isso não quer dizer que os aportes filosóficos estejam já à disposição para um "encaixe filosófico". Nesse sentido, não existem suficientes metáforas nem analogias, nas três escolas apresentadas, para um "acoplamento" que venha atender à complexidade do rompimento paradigmático decorrente dos elementos tecnológicos presentes na contemporaneidade. Além disso, o direito de autor não é o "único modelo de direito", devendo ser visto como uma

\footnotetext{
${ }^{15}$ Não obstante tal fato deve-se compreender que dentre esses pensadores, definitivamente, Kant foi o que mais se aproximou de construir soluções e alimentar ideias que conduzissem a um sistema de direito de autor.

${ }^{16}$ Como é o entendimento de BOWREY: Escritores têm mapeado a influência de filósofos como Locke, Kant e Hegel sobre as reivindicações proprietárias dos autores, no entanto eles têm tratado do direito de autor como um projeto inacabado. A lei não foi capaz de reproduzir fielmente o pensamento claro dos filósofos, e, como tal, continua a ser inadequada, sem princípios e inconstante no tratamento de 'direito do autor'. Traduzido de Writers have mapped the influence of philosophers such as Locke, Kant and Hegel on the proprietal claims of authors, however these writers have treated copyright as an unfinished project. The law has failed to faithfully reproduce the clear thinking of the philosophers, and as such it remains inadequate, unprincipled and inconstant in the treatment of the author's "right". BOWREY, Kathy. The Outer Limits of Copyright Law - Where Law Meets Philosophy and Culture, Law and Critique, Disponível em <http://www.chickenfish.cc/copy/> . Acesso em 22 set. 2016. O entendimento da autora faz eco com o entendimento deste estudo sobre a (in)adaptabilidade das teses filosóficas dos autores, considerando que suas reflexões foram, em sua maioria, de ordem bem distinta da temática do direito de autor.
} 
O CONCEITO DE CÍRCULO CRIATIVO: PORQUE A VIRAGEM LINGUÍSTICA INTERESSA FILOSOFICAMENTE AO DIREITO DE AUTOR

VICTOR GAMEIRO DRUMMOND

categoria em evolução, mas desde que não se tomem "atalhos" para a compreensão de suas origens filosóficas e para a sua função social. ${ }^{17}$

Como se verá, a tese indicada neste estudo aponta para a defesa da aplicabilidade da hermenêutica contemporânea (basicamente de matriz heideggeriana e gadameriana), justificando detalhadamente as motivações para tal. Ainda que não haja, também no caso deste estudo, uma aplicabilidade absoluta como se fosse uma teoria filosófica construída pelos filósofos analisados e voltada ao direito de autor, a tese ora apresentada justifica plenamente a adaptação a ser difundida, especialmente, por estar voltada à compreensão dos fenômenos filosóficos decorrentes da invasão da filosofia da consciência pela filosofia da linguagem. Este fenômeno atingiu (ainda de modo incipiente) o Direito, e o que se pretende comprovar neste estudo é que também o fez com o direito de autor, o que não parece ter sido matéria de apreciação, seja pelos autoralistas, seja pelos próprios filósofos (do Direito ou não).

Ocorre que podem ser observadas nas análises das teses justificantes pelo menos quatro pontos de prejuízo a conclusões efetivas sobre a inaplicabilidade das mesmas: $1 .^{\circ}$ ) a análise do direito de autor dá-se, na contemporaneidade, no sentido de efetuar um corte para solucionar um problema primordialmente econômico; $2 .^{\circ}$ ) há uma busca por uma justificativa filosófica para solucionar problemas essencialmente econômicos; $3 .^{\circ}$ ) as análises efetuadas pelos autoralistas têm como objetivo justificar a flexibilização do direito de autor hoje (e o direito de autor de hoje), e não, a sua existência como categoria desde o seu surgimento; $4 .^{\circ}$ ) em nenhuma das análises se observou o direito de autor sob o olhar da invasão da filosofia pela linguagem nas perspectivas do giro linguístico, mas sempre se desejando adaptar, por exemplo, as teses de Locke àquele momento histórico de surgimento do direito de autor ou ao momento atual sem compreender a sua inaplicabilidade na contemporaneidade, em decorrência do fato de que a filosofia hoje imperante é outra.

Estas razões, simplesmente, já seriam suficientes para se buscar construir uma tese que justificasse plenamente a existência do direito de autor como categoria jurídica. 0 mais relevante, pois, é compreender que o processo criativo decorre da observação e interpretação do mundo por parte do sujeito-criador e a aplicabilidade um não de uma categoria jurídica deve ser observada sob o olhar filosófico que responda à questão: por que se deve (ou não se deve)

\footnotetext{
${ }^{17}$ A função social, por sua vez, é uma medida interessante de solução para alguns conflitos de direito de autor e propriedade intelectual, mas possui valor densamente econômico como solução pragmática à crise do direito de autor. De toda forma, é uma dentre as soluções de relevo e que fazem parte de uma discussão interna do direito, estando prevista na constituição de alguns países, como é o caso do Brasil (CRFB, Art. 170, inciso III).
} 
O CONCEITO DE CÍRCULO CRIATIVO: PORQUE A VIRAGEM LINGUÍSTICA INTERESSA FILOSOFICAMENTE AO DIREITO DE AUTOR

VICTOR GAMEIRO DRUMMOND

atribuir a condição de autor a um sujeito-criador e quais as consequências deste ato? Este estudo pretende dar uma resposta a esta questão, observando o direito de autor como categoria autônoma de direito e cuja necessidade evidente é dialogar com a filosofia, mormente, no entender deste estudo, com a hermenêutica.

\section{A NECESSIDADE DE APLICAÇÃO DE UMA TEORIA FILOSÓFICA VOLTADA EXCLUSIVAMENTE AO DIREITO DE AUTOR}

A compreensão do processo criativo e a tentativa de equilíbrio entre o que o criador pode extrair do universo à sua volta e o que pode ser objeto de proteção em decorrência do seu processo criativo vem sendo indicada como um elemento necessário à compreensão e aplicação do direito de autor. 0 confronto entre o aporte individual do criador e o que ele recebeu do mundo como contributo para o conduzir à criação é talvez o ponto de maior relevo para as discussões de direito de autor, desde o seu surgimento efetivo e ainda preambular como categoria jurídica no início do século XVIII ${ }^{18}$.

Este sensível aspecto aparece em diversas relações fundamentais do direito de autor, como por exemplo nos catálogos de limitações de direito de autor (para possibilitar um maior acesso a obras por parte de terceiros) e na própria condução do tema do período de proteção por meio da atribuição de exclusividade ao criador, em oposição ao ingresso da obra no domínio público, situação que tornará prescindível o requerimento para seu uso.

Ocorre que esta problemática tem sido vista, exclusivamente, sob o viés comercial $^{19}$, considerando-se a necessidade de circulação de obras para a sociedade, ou mesmo sob o viés do

\footnotetext{
${ }^{18}$ A este respeito, verificar os diversos estudos doutrinários e fontes primárias de direito de autor na base de dados Primary Sources on Copyright (12450-1900) em http://copy.law.cam.ac.uk/cam/index.php. Também, a este respeito, ver: DRUMMOND, Victor Gameiro. Os privilégios monopolistas como elementos comuns para os sistemas de Copyright e de Droit D'auteur e o déficit filosófico do direito de autor. In: VICENTE, Dário de Moura (coord.). Estudos de Direito Intelectual em Homenagem ao Professor Doutor José de Oliveira Ascensão: 50 anos de vida universitária, Coimbra: Almedina, 2015.

${ }_{19}$ Como corretamente indicam Boldrin e Levine: “Embora exista um furioso debate sobre direito de autor (copyright) e patentes, existe um consenso geral que alguma proteção é necessária para assegurar aos inventores e criadores o fruto dos seus trabalhos. A retórica de que "a informação deve ser livre" sugere que à ninguém seria permitido tirar proveito de suas ideias. Além disto, parece não haver um grande lobby argumentando que enquanto está correto para todos nós - não inventores ou criadores - obter benefícios com o fruto do nosso trabalho, inventores e criadores deveriam se submeter `a caridade alheia. Para além do aspecto emocional, porém, parece haver um acordo entre ambos os lados que as normas de "propriedade intelectual" precisam encontrar um equilíbrio entre possibilitar incentivo suficiente para a criação e a liberdade de se fazer uso de ideias já existentes. Dito de outra forma, ambos os lados
} 
O CONCEITO DE CÍRCULO CRIATIVO: PORQUE A VIRAGEM LINGUÍSTICA INTERESSA FILOSOFICAMENTE AO DIREITO DE AUTOR

VICTOR GAMEIRO DRUMMOND

confronto (muitas vezes forçoso) entre o conteúdo das liberdades e a proteção pela exclusividade típica do direito de autor (como se a necessidade de pagamento pelo uso de obras, por exemplo, fosse uma violação do acesso à cultura). Aliás, a ideia de enquadramento de que o direito de autor é uma espécie de "predador natural" do direito de acesso à cultura vem se sedimentando de modo a dificultar as compreensões econômicas e também sobre o que justifica filosoficamente o direito de autor.

Em sentido oposto à maior parte da doutrina dominante deve-se compreender que a evolução do direito de autor do ponto de vista histórico-filosófico exige a aplicação do linguistic turn à uma análise não conseqüencialista que não interprete as justificativas do direito de autor ex post facto (Suthersanen) ou a posteriori (Drummond). Chamar tais adaptações ou tentar aplicar as teses que, no fundo são verdadeiros leitos de procusto e concluir que se dão ex post facto ou a posteriori é o mesmo, servindo somente, tal terminologia, para apontar o acentuado conseqüencialismo autoral predominante na doutrina. As consequências do resultado da proteção pelo direito de autor fornecem argumentos para justificar filosoficamente o direito de autor.

Trata-se, muito amiúde, de conflitos da ordem comercial e da ordem de distintos interesses que, ainda que se baseiem em aspectos exclusivamente comerciais ou jurídicos, e ainda que sejam legítimos, pretendem dar um "banho de filosofia”, para utilizar uma expressão de Streck, somente no que é interessante aos defensores desta ou daquela tese. A discussão, portanto, se dá na ordem do que se pode fazer com as ideias que tenham sido trazidas ao universo inteligível e a discussão que proponho é anterior, do ponto de vista filosófico, a este aspecto $^{20}$.

Somente para citar um exemplo, ainda que seja mais do que evidente que o interesse pela diminuição do prazo de proteção decorre de um interesse pela liberação das obras protegidas ou a flexibilização do usos na Internet por uma liberação dentro do próprio sistema de direito de autor, a justificativa tradicionalmente utilizada é que o autor deve devolver à

concordam que os direitos de "propriedade intelectual" são um mal necessário que estimula a inovação, e o desacordo é onde a fronteira deve ser estabelecida. Para os defensores da "propriedade intelectual" os benefícios do monopólio atual são apenas suficientes; para seus inimigos, os benefícios do monopólio atual são muito altos." MICHELE BOLDRIN, Michele e LEVINE, David K., Against intellectual monopoly. Cambridge: Cambridge University Press, 2008. p.6.

${ }^{20}$ A doutrina autoralista, seja em países do sistema Copyright ou do sistema Droit D'auteur não tem manifestado muito interesse em desenvolver teses de cunho filosófico que sejam justificantes do direito de autor. Exceções são alguns dos textos citados no corpo deste estudo. 
VICTOR GAMEIRO DRUMMOND

sociedade o que dela recebeu, e isto se daria sob a forma de uma flexibilização do direito de autor.

Por outro lado, é bastante atual a discussão inerente à possibilidade de acesso a obras por meio de mecanismos típicos das novas tecnologias, e a Internet novamente se inclui, como se o simples fato de haver alguma cobrança por parte do autor indicasse uma ofensa à liberdade criativa de terceiros.

0 ponto que se pretende salientar, porém, é que se a justificativa para o equilíbrio é de ordem econômica (e sempre é, ainda que disfarçadamente), não é razoável, para dizer o mínimo, pretender a resolução dos conflitos por meio de socorro a fundamentos filosóficos ${ }^{21}$. Neste sentido, o que se propõe é que a análise deva se dar numa ótica efetivamente filosófica, e, especialmente, por meio da compreensão da hermenêutica contemporânea, mormente aquela desenvolvida por Martin Heidegger e Hans-Georg Gadamer.

Assim, se a justificativa para a atribuição de direitos de exclusivo (ou mesmo de remuneração) tiver que ser dada numa ordem da filosofia (como proposto por tendências contemporâneas excessivamente libertarianistas do direito de autor) deve-se utilizar argumentos da ordem filosófica, mas o resultado desta equação não poderá ser utilizado com um viés econômico. Isto é o que se pretende indicar no presente texto.

Compreendidos os antecedentes do tema em análise, há de se recordar que a arte, apesar de parecer desnecessária ao desenvolvimento do ser humano, para muitos, é a própria razão de sua existência, sendo, portanto, um fim em si mesmo. Por outro lado, a condição da arte conduz a uma potencialidade protetiva a todos os sujeitos que façam parte do contexto cultural-social, na qualidade, indistinta, de potenciais autores - criadores de obras do domínio das artes, da cultura e/ou das ciências.

$\mathrm{O}$ artista, o sujeito-criador, consegue trazer algo do universo sensível para o inteligível e é esta sua capacidade que conduz a toda problemática ora em análise.

O que permite esta tradução do sensível para o inteligível é, como se verá, a hermenêutica e a própria existência da linguagem. ${ }^{22} \mathrm{E}$, assim sendo, a hermenêutica deve ser, também, a base filosófica que justifica a aplicabilidade do direito de autor, especialmente por meio do conceito denominado círculo criativo, que se apresenta neste estudo.

\footnotetext{
${ }^{21}$ Sob pena de retóricas artificiais do tipo: a informação deve ser livre.

22 Esclareço que essa "passagem" do sensível para o inteligível não representa um retorno ao dualismo platonista. Na verdade, o sensível, aqui, quer dizer "a priori compartilhado", pré-compreensão, estrutura compreensiva; já o inteligível significa "a explicitação do que se compreendeu". Afinal, como diz GADAMER, interpretar é explicitar o compreendido.
} 


\section{O CÍRCULO CRIATIVO E O DIREITO DE AUTOR}

A criação artística, por sua vez e portanto, se dá na linguagem e desta forma, a linguagem é o locus onde aparece a manifestação artístico-criativa.

Como já foi dito, a linguagem, antes de tudo, é intranscendível ${ }^{23}$. É, pois, a linguagem o que possibilita o desenvolvimento da criação. Seja ela literária, musical ou pictórica, a linguagem não pode ser aprisionada por ser considerada uma coisa entre a criação e o criador. A linguagem não é algo que se utiliza como simples ferramenta, mas faz parte do processo, considerando-se a linguagem na perspectiva do linguistic turn (a viragem linguística). A linguagem é o que coloca o homem no mundo e permite que se participe dele.

O entendimento da hermenêutica contemporânea, iniciada com Schleiermacher, Dilthey e ainda muito mais propalada por Heidegger (na filosofia hermenêutica) e posteriormente Gadamer (na hermenêutica filosófica) de que a linguagem faz parte da hermenêutica como componente e não como um terceiro elemento entre o sujeito e o objeto a ser interpretado (mas como parte do círculo hermenêutico), deve ser observado também pelos autoralistas, para que se possa compreender porque, do ponto de vista filosófico, a criação artística deve ser protegida pelo direito de autor, e, por outro lado, porque não o podem as ideias ${ }^{24}$.

A criação artística é o próprio resultado da hermenêutica decorrente da percepção factual do criador, por meio dos elementos de sensibilidade artística que o compõe ${ }^{25}$ e de sua visão de mundo (Weltanschauung), e que se dá por meio dos sentidos, considerando-se o

\footnotetext{
${ }_{23}^{23}$ D’AGOSTINI, Franca, Analíticos e Continentais. São Leopoldo: Unisinos, 2003.

${ }^{24}$ A concepção de que as ideias não são objeto de proteção do direito de autor está assentada e presente nos dois sistemas principais, o do direito de autor e direitos conexos e no sistema de copyright. Ocorre que este fundamento tornou-se de tal modo universal que não permite abertura de discussões quanto ao que isso significa, mormente do ponto de vista filosófico. E, exatamente por isso se faz necessária a reflexão filosófica sobre o processo de criação e os seus fundamentos. Por outro lado, há dois pontos importantes a serem lançados 'a discussão: quando se fala em possibilidade de proteção de expressão de ideias se está no universo da discussão do objeto de proteção ou do sujeito criativo. Ocorre que do ponto de vista filosófico e da compreensão do circulo hermenêutico não se deve fazer acentuada distinção entre criaçãoobra e criador-artista, pois ambos estão intrinsecamente relacionados, e considerando-se que a criação artística, em meu entender, é interpretação, e por sua vez, compreendendo-se que a linguagem não é mais uma simples ferramenta hermenêutica entre o sujeito e o objeto, a obra está no sujeito, que, por sua vez, está na obra, como a parte e o todo. Não se atentaram parte dos autoralistas que, por esta razão, subsiste a dificuldade em se criar uma doutrina autoralista que não seja cindindo-se esta relação, obra (objeto) e autor (sujeito). Esta cisão, porém, não pode atravessar a compreensão filosófica de que criador-criação estão indissoluvelmente relacionados na sua essência.

${ }^{25}$ Que compõem a sua essência.
} 
O CONCEITO DE CÍRCULO CRIATIVO: PORQUE A VIRAGEM LINGUÍSTICA INTERESSA FILOSOFICAMENTE AO DIREITO DE AUTOR

VICTOR GAMEIRO DRUMMOND

significado que se quer dar àqueles elementos. Esta manifestação faz uso da linguagem, como já se disse. Mas o compreender que se faz uso da linguagem não é a totalidade da problemática, considerando que outros conceitos precisam ser adaptados para conclusão da inserção das teses hermenêuticas à concepção do porquê da proteção da criação artística.

Desta forma, o padrão estabelecido - a necessidade de se equilibrar direito de autor como direitos de exclusivo (ou de remuneração) com direitos de acesso às obras ou direitos inerentes à liberdade criativa em geral - é observado já fora do enfoque filosófico, o que configura um erro. Neste sentido, a relação de (necessário) equilíbrio entre o uso (e o anterior acesso) de uma obra e a criação (e a proteção pela exclusividade pelos direito de autor), não se dá num plano comercial ou mesmo - indo mais além - puramente legal. Dá-se, portanto, num plano filosófico ao compreender que o outro e a resultante da sua manifestação criativa merecem proteção e decorrem de total liberdade e possibilidade existencial da obra ${ }^{26}$.

Por outro lado, e por estes mesmos motivos, não se pode atribuir exclusividade excessiva (por exemplo, às ideias), pois lembrando a lapidar frase de Heidegger, se a linguagem é a casa do ser, tornar-se "senhor" das ideias e enclausurar todas as modalidades de expressão possíveis (pela negativa de sua "libertação" em consequência da exclusividade atribuída) e enclausurando a linguagem por meio de um engessamento pela impossibilidade de libertação das ideias sob nenhuma forma criativa (no sentido de enclausurar a linguagem - e consequentemente o sujeito-criador) - é enclausurar o próprio ser na totalidade que não the pertence. Desta forma, inclusive, se estaria ignorando a diferença ontológica ao não permitir novas criações e manifestações artístico-culturais, pois as ideias estariam aprisionadas na exclusividade de um sujeito que, ao constituir-se como o titular desta exclusividade, seria o ser, em oposição aos demais criadores, potenciais, que seriam considerados entes. Neste caso, e como o ser sempre é o ser de um ente, o ente criador só o seria se pudesse concretizar a(s) ideia(s) sob uma determinada forma. Alcançar a possibilidade criativa, saindo do universo de uma simples ideia para a concretização de uma obra seria a diferença ontológica entre o ser (idealizador) e o ente (concretizador da ideia sob uma forma). Assim, a diferença ontológica estaria entre o ser (que potencialmente poderia criar algo em decorrência de uma ideia não concretizada) e o ente (criador concretizador da sua ideia / concepção) $)^{27}$.

\footnotetext{
${ }^{26} \mathrm{E}$, no mais, se dão num ambiente de criação que, apesar de irrepetível, pode trazer semelhanças. Por esta razão de ordem filosófica o direito de autor protegem a criação e condenam o plágio.

${ }^{27}$ A concepção de que as ideias não são objeto de proteção do direito de autor está assentada e presente nos dois sistemas principais, o do direito de autor e direitos conexos e no sistema de copyrights. Ocorre
} 
O CONCEITO DE CÍRCULO CRIATIVO: PORQUE A VIRAGEM LINGUÍSTICA INTERESSA FILOSOFICAMENTE AO DIREITO DE AUTOR

VICTOR GAMEIRO DRUMMOND

Neste sentido, portanto, e como já foi antecipado, não se pode atribuir o direito de exclusividade às meras ideias e sim à forma que se dará a elas. Exatamente por isso, não se pode impedir a manifestação do sentimento artístico de um criador porque deste modo se estaria enclausurando a linguagem e portanto, desconstituindo filosoficamente o conceito da criação de um ser (potencialmente) criativo.

Ocorre que do ponto de vista do ser criativo (sujeito-criador) toda a interpretação é irrepetível $^{28}$ e do ponto de vista filosófico uma obra nunca será igual a outra e todas são permitidas se as sua origens forem distintas, se criação for espontânea e filosoficamente livre. Neste sentido, a proteção recairá sempre e somente sobre a forma e nunca sobre o conteúdo.

Desta forma, do ponto de vista do ser criativo é como se houvesse "uma resposta correta" para cada sentimento que se manifestasse de determinado modo, em determinadas condições, em determinadas circunstâncias e, com determinado resultado a que se denomina criação artístico-cultural. Ao se permitir a proteção de simples ideias se estaria ignorando a diferença ontológica e transformando um ser (criador na sua potencialidade por alcançar uma determinada ideia) num ente (criador, efetivamente concretizador das ideias em obras), misturando-se o conceito de obra com o de ideia, e o do potencial criador (ser - potencial criador - aquele que "ob-teve" uma ideia) com o do efetivo criador (ente - criador ou potencial (sujeito) criador - aquele que desenvolveu a ideia sob determinada forma).

A criação intelectual artística, portanto, é interpretação ${ }^{29}$. É compreensão do mundo e também do dado em outras obras pré-existentes (das obras dadas) na geração/criação do criado, na própria compreensão, no sentido elaborado/desvelado pelo criador. É criação que surge no ambiente do intérprete sob o olhar dos três momentos fundamentais indicados por Heidegger

que esta fundamento tornou-se de tal modo universal que não permite abertura de discussões quanto ao que isso significa, mormente do ponto de vista filosófico. E, exatamente por isso se faz a necessária a reflexão filosófica sobre o processo de criação e os seus fundamentos. Por outro lado, ha dois pontos importantes a serem lançados: quando se fala em possibilidade de proteção de expressão de ideias se está no universo da discussão do objeto de proteção ou do sujeito criativo. Ocorre que dom ponto de vista filosófico e da compreensão do circulo hermenêutico não se deve fazer acentuada distinção entre criaçãoobra e criador-artista, pois ambos estão intrinsecamente relacionados, e considerando-se que a criação artística, em meu entender, é interpretação, e por sua vez, compreendendo-se que a linguagem não é mais uma ferramenta hermenêutica entre o sujeito e o objeto, a obras está no sujeito, que está na obra, como a parte e o todo. Não se atentaram parte dos autoralistas que, por esta razão, subsiste a dificuldade em se criar uma doutrina autoralista que não seja cindindo-se esta relação, obra (objeto) e autor (sujeito). Esta cisão, porém, não pode atravessar a compreensão filosófica de que criador-criação estão indissoluvelmente relacionados.

${ }^{28}$ Valendo também lembrar que a hermenêutica trabalha a partir da produção de sentidos - Singebung.

${ }^{29} \mathrm{~A}$ interpretação aqui não se atribui no sentido de interpretação como motivação/objeto de proteção dos direitos conexos (como uma vertente de criação protetiva dos direitos conexos) mas como interpretação no sentido filosófico de ver-o-mundo. 
O CONCEITO DE CÍRCULO CRIATIVO: PORQUE A VIRAGEM LINGUÍSTICA INTERESSA FILOSOFICAMENTE AO DIREITO DE AUTOR

VICTOR GAMEIRO DRUMMOND

(aquisição prévia -Vorhabe; vista prévia - Vorsicht e antecipação - Vorgriff ${ }^{30}$ ). É isto que justifica compreender que a interpretação (exteriorizada) sob uma determinada forma, permite a exclusividade, desde que esta exclusividade não impeça a livre criação, desde que a nova criação não seja ofensiva da anterior, ou uma mera cópia. Isto se dá num ambiente filosófico e não econômico ou comercial ${ }^{31}$.

Diante dos argumentos apresentados, há de se compreender, que no entender da hermenêutica contemporânea, o processo de criação artística está presente no que se denomina círculo hermenêutico, conceito filosófico que, entre outras várias compreensões, indica que do ponto de vista da hermenêutica a parte está no todo e o todo sempre deve ser interpretado em conjunto com a parte. Esta conceituação serve como fundamento para a compreensão de textos em sua integralidade e em suas distintas partes, como também serve como fundamento para qualquer interpretação discursiva ou simbólica, que sempre deverá ser observada em seu contexto, em seu ambiente. Por isto, por vezes, destacar-se um texto, uma fala, uma sinalização, pode condenar a parte destacada (e seu autor), pela sua (equivocada) compreensão fora do todo.

Ainda sobre o conceito de círculo hermenêutico, cumpre ressaltar que antes mesmo de Heidegger e Gadamer, foi Schleiermacher quem o desenvolveu, ainda que este autor tratasse da hermenêutica demasiadamente voltada à interpretação das escrituras, considerando sua formação de homem da religião. Dizia o teólogo alemão que: “... assim como o todo seguramente é compreendido a partir do particular, também o particular apenas pode ser compreendido a partir do todo...".

Ou seja, compreendia o filósofo que “... o princípio hermenêutico...” que, portanto, conduzia à compreensão do sentido do círculo hermenêutico:

\footnotetext{
${ }^{30}$ Utiliza-se a tradução dos momentos fundamentais/elementos existenciais heideggerianos de Ernildo Stein, que, inclusive, irá explicitá-los com bastante precisão em seu artigo Breves considerações históricas sobre as origens da filosofia no Direito. In: IHJ - Instituto de hermenêutica jurídica. A filosofia no Direito e a filosofia do Direito, Porto Alegre: 2007 a partir da página 106: O filósofo (Heidegger), articula, com sua analítica existencial, um conjunto de existenciais que configuram as estruturas do ser-aí. Mas estas estruturas não são qualidades empíricas, psicológicas, por exemplo. Não representam também elementos simplesmente formais, lógicos, apenas conceitos. Por isso, o compreender com os elementos da aquisição prévia (Vorhabe), vista prévia (Vorsicht) e antecipação (Vorgriff), deve ser entendido em sua complexidade.

${ }^{31}$ E assim como a questão do plágio vai se dar, também, na necessidade de observar uma relação de equidade e justiça vão se dar no uso de obras, as quais, por diversos setores da sociedade querem afastar a aplicação legal.
} 
O CONCEITO DE CÍRCULO CRIATIVO: PORQUE A VIRAGEM LINGUÍSTICA INTERESSA FILOSOFICAMENTE AO DIREITO DE AUTOR

VICTOR GAMEIRO DRUMMOND

[...] é de tal alcance para esta arte, e tão indiscutível que já as primeiras operações não podem ser estabelecidas sem o seu emprego, visto que uma grande quantidade de regras hermenêuticas repousam mais ou menos sobre ele. Seja uma palavra cujo valor linguístico geral é conhecido: a parte desse valor linguístico que se aplica na passagem dada e aquelas que devem ser excluídas, apenas será determinada através das outras partes da mesma frase e, primeiramente, 'aquelas com as quais ela tem uma relação orgânica mais próxima, o que significa, portanto, que ela é compreendida como parte do todo, com elemento do conjunto. $E$ isto não vale apenas para a escolha entre os assim chamados múltiplos significados de uma palavra, mas também em todas as palavras que são suscetíveis de gradações diferentes, para esta gradação mesma e, de uma maneira geral, para a maior ou menor ênfase atribuída a uma palavra. $^{32}$

Obviamente que o conceito de Schleiermacher não contemplava a criação artística, pois esta não era uma preocupação sua, mas, como criação artística é interpretação, no sentido filosófico, o todo pode ser aqui concebido como uma série de outras complexidades observáveis do ponto de vista da anterioridade existencial de obras e criadores, tais como: 1 - a totalidade de obras pré-existentes; 2 - a totalidade e a complexidade de escolas e/ou estilos de criações artísticas; 3 - a complexidade das totalidades de potencialidades de criação; e todos os elementos que podem conduzir aos elementos gadamerianos da tradição e/ou da facticidade heideggeriana, considerando, em todas as suas hipóteses, os existenciais da filosofia hermenêutica heideggeriana (Vorhabe; Vorsicht e Vorgriff).

Dito de outro modo, o círculo hermenêutico pode ser compreendido como o locus onde se dá a criação, e, este locus, como se percebe, não é um vazio, um mundo das ideias platônico e estático à espera de um "criador-condutor" de sua captura para dar vida à sua plenitude existencial.

Por outro lado, este conceito circular e de complexidade filosófica pode (e deve) ser compreendido no âmbito da criação artística, visto que uma criação artística nunca é uma criação artística fora do contexto. A obra é parte de um todo. 0 todo que é o ambiente do qual ela surge, o qual representa a totalidade. Também o todo que é composto por todas as obras do artista que a criou. Igualmente do todo das criações artísticas postas antes dela mesma. Ela sempre se relaciona com seu sujeito-criador, que por sua vez, igualmente compõe parte de um todo. E pela compreensão do fato do ser criativo encontrar-se num mundo posto, este já é

32 SCHLEIERMACHER, Friedrich D. E., Hermenêutica: Arte e técnica da interpretação. 2. ed. Petrópolis: Vozes, 2000, p. 47. 
O CONCEITO DE CÍRCULO CRIATIVO: PORQUE A VIRAGEM LINGUÍSTICA INTERESSA FILOSOFICAMENTE AO DIREITO DE AUTOR

VICTOR GAMEIRO DRUMMOND

influenciado pela percepção das criações artísticas já postas ${ }^{33}$. A esta concepção do círculo hermenêutico no ambiente das criações artísticas é que se nomeia deste estudo por círculo criativo.

O círculo hermenêutico aqui compreendido sob a forma de círculo criativo, pois, possibilita que a $\operatorname{arte}^{34}$ (e a interpretação do ser criativo) se manifeste, considerando-se seus antecedentes, em uma criação artística. O quanto desta criação deve ser atribuída ao autor (sujeito-criador) é algo que não se pode mensurar no campo do direito de autor sem a compreensão do círculo hermenêutico, agora compreendido sob nova roupagem. E mesmo a origem da obra em si, não pode sofrer mensuração qualitativa considerando antecedentes sem a compreensão do círculo hermenêutico/criativo. A tarefa filosófica do direito de autor é dizer o quanto o criador pode e deve ser protegido por ter trazido ao mundo perceptível dos sentidos algo que se plasmou sob a forma de uma criação artística. Neste sentido, entendo que o que está posto como antecedente à criação concretizada no círculo criativo, exige, de fato, um retorno a seu lugar de origem, considerando a possibilidade de circularidade. Isto, porém, não pode ser visto sob o olhar econômico ou do direito sem apreciação da compreensão filosófica deste olhar do momento e do locus da criação. Do ponto de vista filosófico, tudo isto se justifica, mas não por meio de uma imposição de ordem econômica ou jurídica.

\footnotetext{
33 Vem se desenvolvendo com bastante profusão, especialmente nos Estados Unidos da América, teses de que o processo criativo deveria ser relativizado no que se refere à proteção pelo direito de autor. As teses basicamente, atribuem, como já indiquei, fundamentos muito mais presentes no âmbito econômico e da liberdade de acesso à cultura e liberdade de criação do que pontuações filosóficas. 0 autor norte americano Lewis Hyde, na sua obra A dádiva foge um pouco a esta regra pois indica um posicionamento de ordem filosófica, afastando-se em sua tese, dos meros argumentos econômicos ou excessivamente libertários de outros autores, ainda que eu não esteja de acordo com parte significativa de sua tese.

Em linhas gerais, o autor busca adequar a questão do que pode ser considerado como criação artística e que, esta criação deve circular socialmente como uma doação. Em algum sentido, o que é defendido pelo autor norte americano é uma concepção de que deve estar intrínseca à criação o fato de que a circulação artística é (para dizer o mínimo) melhor se se fizer com uma transmissão de uma dávida que foi recebida e que, portanto, não poderia deixar de circular. Assim, parece indicar o autor que, uma vez compreendido que um autor é um criador de uma obra de arte, este deve permitir a sua circulação social pois somente pode cria-la por ter recebido, sob a forma de dávida e um autor anteriormente alimentado por alguma criação. Este círculo vicioso-virtuoso seria fundamental para a criação artística estimulante para a possibilidade de novas criações. Melhor dizendo, em linhas gerais, defende o autor que somente desta forma haveria um novo processo criativo. Além de $A$ dádiva de Lewis Hyde e das obras de Lawrence Lessig em geral, outros textos que apresentam um viés também excessivamente libertarianista mas que merecem alguma atenção pelos estudos implementados ou por algumas teses apresentadas são: Copyrights and copywrongs, The rise of intelectual property and how it threatens creativity, de Siva Vaidhyanathan e The soul of creativity, forging a moral rights law for the United States, de Roberta Rosenthal Wall, Stanford University Press, Stanford: 2009.

${ }^{34} \mathrm{E}$ o conhecimento e a percepção sensível do criador.
} 
O CONCEITO DE CÍRCULO CRIATIVO: PORQUE A VIRAGEM LINGUÍSTICA INTERESSA FILOSOFICAMENTE AO DIREITO DE AUTOR

VICTOR GAMEIRO DRUMMOND

Outra questão importante é que os sentidos podem ser ativados de modo diferente de acordo com cada concepção artística e tipos de obras. Ou seja, não se pode falar que uma obra pode ser protegida porque se plasma sob determinada forma conceptível (concebível) dos sentidos. Ou seja, pode haver uma proteção de algo que tenha como manifestação o som, mas a literatura, por exemplo, por sua abstração, não vai permitir, no momento de sua primeira percepção de existência como obra uma manifestação direta, a concepção daquelas mesmas ideias, que se manifestariam sob uma forma mais abstrata. O círculo criativo será assim invadido de modos diferenciados por/para cada modalidade de expressão artística. E, considerando que o autor (sujeito-criador) poderá criar sob distintas formas, o momento da escolha da forma da criação é, também um momento de criação. E tudo isto se dá no círculo criativo e, considerando-se que este compõe-se de um todo infinito de possibilidades, as diversas modalidades de manifestações artísticas são potencializadas por cada possível sujeito criador ${ }^{35}$.

No contexto do círculo criativo outra colocação que pode ser feita é se a obra vem antes do artista ou não. O ainda, se o artista vem antes da obra, mas (se) a obra já "está" (no mundo). A obra não é (obra), mas já está (potencialmente, no mundo). E ela está no artista ou não. Ou seja, do ponto de vista filosófico não faz tanto sentido dizer que somente há obra porque há artista, pois esta obra poderá “estar" se houver outro artista. E como sempre haverá outro artista, a obra sempre é, ainda que não esteja. (A obra) Só não seria, se não houvesse nenhuma possibilidade, ou seja, se não houvesse nenhum sujeito, o que não traria discussão, nem esta mesma que ora se propõe. Sendo mais claro, a (potencial) criação é inerente a todo e qualquer sujeito, sendo ele - categorizado como capaz de criar ou não. Neste sentido, pode-se dizer que a obra, se é o nada - por não existir - é/está nadificada e, com isto toda a obra já existe (potencialmente, porém previamente nadificada). Neste sentido e sobre este ponto de vista filosófico toda obra já sempre está e, portanto, nunca será oriunda de um artista, mas sempre de um artista e dela mesma em seu locus, sendo portanto, a obra, ela mesma, parte do círculo criativo. Isto justifica, ao mesmo tempo, que exista uma proteção ao criador que concretizou a

35 Por isso, a concepção e aplicação de exclusividade de ideias, mas que não permitir o livre desenvolvimento criativo de terceiros que não possuam a exclusividade, traria a potencialidade de que a apropriação exclusiva da linguagem poderia se dar sob diversas manifestações artísticas. Esta invasão das fronteiras das potencialidades de quaisquer manifestações poderia, ao fim e ao cabo, conduzir a uma simplificação tamanha que quem observasse que uma manifestação ideal fosse compatível com diversas formas estaria se apropriando do modo mais efetivo da linguagem artística. Para ser mais claro, alguém que tencionasse criar uma composição musical sobre traição poderia ser titular desta exclusividade no âmbito musical e, considerando-se a potencialidade e a integração entre formas de criação, qualquer obra, de qualquer modalidade que contivesse esta simples menção ideológica já estaria escravizada na proteção do idealizador não concretizador. 
O CONCEITO DE CÍRCULO CRIATIVO: PORQUE A VIRAGEM LINGUÍSTICA INTERESSA FILOSOFICAMENTE AO DIREITO DE AUTOR

VICTOR GAMEIRO DRUMMOND

potencialidade da obra existente no nada, mas que deva ao mesmo tempo ser considerada a pré-existência da obra, ainda que nadificada.

Por outro lado, uma obra é composta de uma parte no todo que é a carreira produtiva do artista. Recorrendo novamente ao conceito de círculo hermenêutico, pode-se considerar que a parte do circulo criativo que compõe o universo dos sentidos perceptíveis pelo ser humano deve conduzir à compreensão de que o todo não pode ser protegido por exclusividade, pois que se assim o fosse, não seria possível surgir mais partes destacadas(veis) e criadas. Por outro lado, a proteção do todo não é razoável, pois não se pode proteger tudo, retirando tais conceitos vagos do universo (como seriam as ideias). A noção de círculo hermenêutico, presente em Schleiermacher, Gadamer e Heidegger pode ser compreendida à luz do direito de autor (na forma adaptada do círculo criativo) como uma análise hermenêutica e da compreensão de que todo o potencial criativo humano deve ser potencializado sempre ao máximo, mas, ao mesmo tempo deve se observar que a parte pode ser indicada pelo sujeito-criador (hermeneuta) que conseguiu, com sua capacidade interpretativa, trazer parte do todo a uma concepção artística. Esta parte do todo, concretizado, e que pode ser objeto de proteção pelo direito de autor, será portanto, concretizada sob a forma (e, portanto, os casos são sempre concretos, na interpretação jurídica) de obra inteligível e protegível.

Há, portanto, dois elementos importantes nesta concepção: em primeiro lugar a compreensão que num meta círculo hermenêutico/criativo potencial e comunicativointerpretativo existem todas as criações artísticas em sua potencialidade e que, somente a existência de todo o universo criativo não seria passível de proteção, mas que parte deste universo sim, ainda que faça parte do círculo criativo em sua totalidade. Em segundo lugar, este ambiente circunstancial conduz à possibilidade de proteção, por meio do direito, do resultado da interpretação artística operada pelo sujeito-criador, que é a obra protegível. Este sujeitocriador, para criar, terá ingressado no círculo hermenêutico, que, neste caso, denomina-se círculo criativo.

O salto no círculo criativo (como no círculo hermenêutico) pode se dar por uma criação mais ou menos original em sentido de anterioridade (de criação) conhecida ${ }^{36}$.

Em suma, como não há "porta de entrada" no círculo hermenêutico não se pode identificar, efetivamente, se o início primordial (o gene fundamental) da criação foi o sujeito em sua (profunda) criação interna mais distante. Do ponto de vista da hermenêutica não há um

\footnotetext{
${ }^{36}$ Porque muito provavelmente parte da criação já foi pré-criada/surgida (se se quiser utilizar esta concepção de surgimento - por outro ente, como se pode compreender.
} 
O CONCEITO DE CÍRCULO CRIATIVO: PORQUE A VIRAGEM LINGUÍSTICA INTERESSA FILOSOFICAMENTE AO DIREITO DE AUTOR

VICTOR GAMEIRO DRUMMOND

criador originário fundamental mas o ser-aí também no ambiente de criação - interpretação do mundo e a sua Weltaunschaung) conduz a uma ou outra criação).

E por fim, a compreensão do círculo criativo, pois, como uma adaptação do círculo hermenêutico ao universo da criação do domínio das rates da cultura e/ou das ciências é, portanto, elemento fulcral para se alcançar a justificativa filosófica para a aplicabilidade do direito de autor.

\section{CONCLUSÃO}

O direito de autor, como pode ser percebido pelo presente estudo, deveria dialogar com mais frequência com outras áreas do conhecimento e, particularmente, com a filosofia.

Uma vez alcançado um diálogo denso, como o que se pretende no presente texto, devese partir para a compreensão da(s) verdadeira(s) justificativa(s) para a aplicação do direito de autor a um sujeito-criador.

A teoria do direito de autor, devidamente observada à luz da invasão da filosofia pela linguagem na viragem linguística (linguistic turn) e da hermenêutica filosófica gadameriana e da filosofia hermenêutica heideggeriana, deve ser o ambiente de proteção da criação que se dá por um processo hermenêutico de compreensão de circunstâncias observadas pelo sujeito-criador num universo amplo e que são levadas à cabo pela hermenêutica no processo da criação artística. A proteção da potencialidade (que seria representada pelo todo) não é possível, mas da parte sim (que seria representada pela obra concretizada e exteriorizada), pois esta se deu sob a forma concretamente realizada por meio de obra(s) em termos hermenêuticos e não meramente potenciais. Isto explica, também, a concepção de que o circulo hermenêutico estará inserido num contexto em que pré-juízos/pré-conceitos são compreendidos do ponto de vista do sujeito-criador, como parte da subjetividade que, por sua vez, compõe, também o circulo hermenêutico onde surge a obra como criação artística (portanto, o círculo criativo).

Diante de todo este panorama e analisado o processo de criação artística como hermenêutica do que está posto e dado no mundo, o sujeito-criador de obra artística merece a sua remuneração ou compensação, sem detrimento de que o todo não pode ser protegido por meio de exclusividade, sob pena de enclausuramento da manifestação da linguagem. 
O CONCEITO DE CÍRCULO CRIATIVO: PORQUE A VIRAGEM LINGUÍSTICA INTERESSA FILOSOFICAMENTE AO DIREITO DE AUTOR

VICTOR GAMEIRO DRUMMOND

A tarefa do direito de autor é analisar o quanto desta proteção deve ser efetuada sob a forma de exclusividade ${ }^{37}$ em detrimento do que deve continuar sendo componente de um todo ainda não desvelado sob a forma de obra artística, para que não se operem injustiças (negando o valor de contemplações subjetivas artísticas de ordem criativa) e que não se atribuam enclausuramentos potenciais excessivos (impossibilitando o desenvolvimento de obras). A tarefa do direito de autor, portanto, é o enquadramento e o estabelecimento dos limites da categoria jurídica em apreciação.

Parte do que foi apresentado neste texto já foi compreendido pelos autoralistas, mas sempre isoladamente do contexto hermenêutico, e o que se pretende, com a concepção ora apresentada, é demonstrar que as questões de ordem econômica ou de outros valores mormente jurídicos - devem se amparar nos fundamentos filosóficos, considerado que a hermenêutica é o caminho mais justo e efetivo à busca da verdade filosófica, e, admitindo-se a invasão da linguagem como parte do mundo jurídico e não como mera ferramenta, também se alcançará a verdade jurídica.

E a verdade que aqui é buscada e deve ser compreendida é a justificativa do direito de autor ao sujeito-criador, circunstância que somente pode ser efetivamente justificada filosoficamente ao se aceitar a existência do círculo criativo como locus/momentum do processo criativo.

\section{REFERÊNCIAS}

BARBOSA, Roberto Garza. Derechos de autor y derechos conexos: marco jurídico internacional, aspectos filosóficos, sustantivos y de litigio internacional. Ciudad de México: Porrúa, 2009.

BOLDRIN, Michele e LEVINE, David K., Against intellectual monopoly. Cambridge: Cambridge University Press, 2008.

BOWREY, Kathy. The Outer Limits of Copyright Law - Where Law Meets Philosophy and Culture, Law and Critique, Disponível em <http://www.chickenfish.cc/copy/> . Acesso em: 22 set. 2016.

D’AGOSTINI, Franca, Analíticos e Continentais. São Leopoldo: Unisinos, 2003.

DRAHOS, Peter. A philosophy of intellectual property. London: Ashgate Publishing Limited, 1996.

\footnotetext{
${ }^{37}$ Ou sob a forma de direitos de remuneração.
} 
DRUMMOND, Victor Gameiro. Os privilégios monopolistas como elementos comuns para os sistemas de Copyright e de Droit D'auteur e o déficit filosófico do direito de autor. In: VICENTE, Dário de Moura (coord.). Estudos de Direito Intelectual em Homenagem ao Professor Doutor José de Oliveira Ascensão: 50 anos de vida universitária, Coimbra: Almedina, 2015.

FISHER, William, Theories of intellectual property. Disponível em: <http://cyber.law.harvard.edu/people/tfisher/iptheory.pdf>. Acesso: 20 set. 2016.

GADAMER, Hans-Georg. Verdade e Método: Traços fundamentais de uma hermenêutica filosófica. 9. ed. Petrópolis: Vozes, 2008.

GADAMER, Hans-Georg, Verdade e Método II: Complementos e índice. 9. ed. Petrópolis: Vozes, 2002.

GADAMER, Hans-Georg, Esboços do fundamento de uma hermenêutica. In: FRUCHON, Pierre (coord.). O problema da consciência histórica. Rio de Janeiro: Fundação Getúlio Vargas, 1996.

GADAMER, Hans-Georg, Problemas epistemológicos das ciências humanas, in 0 problema da consciência histórica. In: FRUCHON, Pierre (coord.). O problema da consciência histórica. Rio de Janeiro: Fundação Getúlio Vargas, 1996.

GADAMER, Hans-Georg, A razão na época da ciência. Rio de Janeiro: Tempo Brasileiro, coleção Biblioteca Tempo Universitário volume 72, 1983.

HEIDEGGER, Martin, Ser e Tempo. 3. ed. Rio de Janeiro: Vozes, 2008.

HEIDEGGER, Martin, A origem da obra de arte. São Paulo: Edições 70, 2010.

HYDE, Lewis, Dádiva e a origem da obra de arte. Rio de Janeiro: Civilização Brasileira, 2011.

KANT, Immanuel. On the Injustice of Reprinting Books. Disponível em <http://copy.law.cam.ac.uk/cam/tools/request/showRepresentation?id=representation_d_178> . Acesso em: 03 out. 2016.

MERGES, Robert P. Justifying intellectual property. Cambridge/London: Harvard University Press, 2011.

PECES BARBA, Gregorio; FERNÁNDEZ, Eusebio; ASÍs, Rafael de; Curso de Teoría del Derecho, Madrid: Marcial Pons, 2000. 


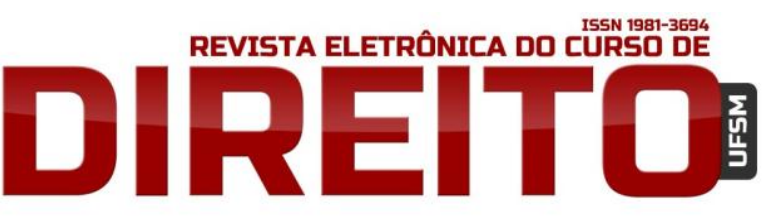

O CONCEITO DE CÍRCULO CRIATIVO: PORQUE A VIRAGEM LINGUÍSTICA INTERESSA FILOSOFICAMENTE AO DIREITO DE AUTOR

VICTOR GAMEIRO DRUMMOND

Reino Unido. Estatuto da Rainha Ana / Queen Anne Statute, Primary Sources on Copyright. London, 1710. disponível em Disponível em:

<http: / / www.copyrighthistory.org/cam/tools/request/showRecord.php?id=record_uk_1710 >. Acesso em 03. out. 2016.

SCHLEIERMACHER, Friedrich D. E., Hermenêutica: Arte e técnica da interpretação, $2^{a}$ edição, Vozes, Petrópolis: 2000.

SILVA, Vasco Pereira da, A cultura a que tenho direito: Direitos fundamentais e cultura.

Coimbra: Almedina, 2007.

STEIN, Ernildo, Breves considerações históricas sobre as origens da filosofia no Direito. In: IHJ Instituto de hermenêutica jurídica. A filosofia no Direito e a filosofia do Direito, Porto Alegre: 2007.

STEIN, Ernildo, Gadamer e a consumação da hermenêutica. In: STEIN, Ernildo; STRECK, Lenio. (coord.). Hermenêutica e Epistemologia: 50 anos de Verdade e Método. Porto Alegre: Livraria do Advogado, 2011.

STRECK, Lenio Luiz, Verdade e consenso: uma teoria da decisão. Rio de Janeiro: Forense, $5^{a}$ edição, 2006.

STRECK, Lenio Luiz, Hermenêutica e decisão jurídica: questões epistemológicas. In: STEIN, Ernildo; STRECK, Lenio. (coord.). Hermenêutica e Epistemologia: 50 anos de Verdade e Método. Porto Alegre: Livraria do Advogado, 2011.

SHUTERSANEN, Uma, A Stakeholder's Palimpsest. In F. Macmillan (coord.), Copyright Law: New Directions in Copyright Law. London: Edward Elgar, 2007. 